\title{
Estimating supraglacial lake depth in West Greenland using Landsat 8 and comparison with other multispectral methods
}

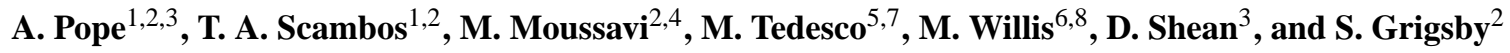 \\ ${ }^{1}$ National Snow and Ice Data Center, University of Colorado, Boulder, Boulder, Colorado, USA \\ ${ }^{2}$ Cooperative Institute for Research in Earth Sciences, University of Colorado, Boulder, Boulder, Colorado, USA \\ ${ }^{3}$ Polar Science Center, Applied Physics Lab, University of Washington, Seattle, Washington, USA \\ ${ }^{4}$ Earth Science and Observation Center, University of Colorado, Boulder, Boulder, Colorado, USA \\ ${ }^{5}$ The City College, of New York, CUNY, New York City, New York, USA \\ ${ }^{6}$ Earth and Atmospheric Sciences, Cornell University, Ithaca, New York, USA \\ ${ }^{7}$ Lamont-Doherty Earth Observatory, Columbia University, Palisades, New York, USA \\ ${ }^{8}$ Geological Sciences, University of North Carolina, Chapel Hill, North Carolina, USA
}

Correspondence to: A. Pope (allen.pope@ post.harvard.edu)

Received: 11 May 2015 - Published in The Cryosphere Discuss.: 22 June 2015

Revised: 12 December 2015 - Accepted: 21 December 2015 - Published: 15 January 2016

\begin{abstract}
Liquid water stored on the surface of ice sheets and glaciers impacts surface mass balance, ice dynamics, and heat transport. Multispectral remote sensing can be used to detect supraglacial lakes and estimate their depth and area. In this study, we use in situ spectral and bathymetric data to assess lake depth retrieval using the recently launched Landsat 8 Operational Land Imager (OLI). We also extend our analysis to other multispectral sensors to evaluate their performance with similar methods. Digital elevation models derived from WorldView stereo imagery (pre-lake filling and post-drainage) are used to validate spectrally derived depths, combined with a lake edge determination from imagery. The optimal supraglacial lake depth retrieval is a physically based single-band model applied to two OLI bands independently (red and panchromatic) that are then averaged together. When OLI- and WorldView-derived depths are differenced, they yield a mean and standard deviation of $0.0 \pm 1.6 \mathrm{~m}$. This method is then applied to OLI data for the Sermeq Kujalleq (Jakobshavn Isbræ) region of Greenland to study the spatial and intra-seasonal variability of supraglacial lakes during summer 2014. We also give coefficients for estimating supraglacial lake depth using a similar method with other multispectral sensors.
\end{abstract}

\section{Introduction and Rationale}

Supraglacial lakes in Greenland play a crucial role in the ice sheet's hydrological system. Together with supraglacial streams (Smith et al., 2015), supraglacial lakes temporarily store large quantities of meltwater which can promote the opening of conduits to the bed through hydrofracture (Das et al., 2008; Phillips et al., 2013; Selmes et al., 2011; Tedesco et al., 2013) and thus influence ice dynamics (Joughin et al., 2013; Parizek and Alley, 2004; Sundal et al., 2011; Zwally et al., 2002). Supraglacial lakes also influence surface heat fluxes by storing latent heat near the surface of the ice sheet (Koenig et al., 2015). Finally, supraglacial lakes contribute to multiple positive feedback processes, including ice shelf disintegration in Antarctica (Banwell et al., 2013; Glasser and Scambos, 2008) and melt-albedo interactions (Leeson et al., 2015).

Several multispectral remote sensing tools and methods exist both for classifying (Johansson and Brown, 2013; Leeson et al., 2013; Sundal et al., 2011) and estimating the depth of supraglacial lakes (Sneed and Hamilton, 2007) in Greenland. MODIS (the MODerate Resolution Imaging Spectroradiometer) is able to provide moderate-resolution $(\sim 250 \mathrm{~m})$ images with large spatial coverage ( $2330 \mathrm{~km}$ swath width) of Greenland twice per day (e.g., Box and Ski, 2007; Fitzpatrick et al., 2014). ASTER (the Advanced Spaceborne Thermal 
Emission and Reflection Radiometer; e.g., Sneed and Hamilton, 2007) and Landsat (e.g., Banwell et al., 2014; Morriss et al., 2013) have higher spatial resolution (10-30 m) but lower spatial coverage and fewer acquisitions (16-day repeat). Commercial sensors, such as DigitalGlobe's WorldView2 and WorldView-3, provide high-resolution multispectral measurements $(\sim 2 \mathrm{~m})$ that can be used to image small water features, such as streams, over smaller areas $(17 \mathrm{~km}$ wide swath) at high temporal and spatial resolution (Chu, 2014; Legleiter et al., 2014; Smith et al., 2015). However, commercial imagery is collected largely "on demand" and cloud cover can still be a confounding factor. Here we provide the first regional-scale validation of supraglacial lake depth estimation methods with all of the above multispectral sensors.

Lake depth retrieval is based upon the understanding that deep water absorbs more energy than shallow water and therefore will have lower reflectance of solar radiation. Some methods use one band for a reflectance-depth relationship, while others use a ratio of reflectances from two different spectral bands (see Sect. 2). Satellite retrieval of supraglacial lake depth is confounded by difficulty measuring the true reflectance of dark/deep lakes, assumptions inherent in the method about minimal quantities of suspended and dissolved matter in lake water, the requirement for a smooth (i.e., not wind-roughened) lake surface, and homogeneous and lowslope lake bottoms (Sneed and Hamilton, 2011). In this study we assume that it is possible to apply locally calibrated coefficients to broad areas (e.g., Legleiter et al., 2014) and that minor variations in effects of atmospheric path radiance can be ignored.

Landsat 8, launched in 2013, hosts a new multispectral sensor, named the Operational Land Imager (OLI), suitable for lake depth estimation. The OLI has enhanced radiometric resolution (12 bit versus 8 bit), a higher signal-to-noise ratio, and an expanded dynamic range compared to Landsat 7's Enhanced Thematic Mapper Plus (ETM+). While published studies (see above) have largely used red and green wavelengths, OLI's two additional bands (coastal, 0.433$0.453 \mu \mathrm{m}$; cirrus, $1.360-1.390 \mu \mathrm{m}$ ) and narrower multispectral and panchromatic bands relative to ETM+, will provide more spectral information and more unique (i.e., less autocorrelated) reflectance values, respectively. These properties lead to improvements for lake depth retrieval methods based on band ratios. Furthermore, an increased scene collection rate by Landsat 8 will lead to more opportunities to observe ice sheets and their supraglacial lakes.

In this paper we investigate retrieval methods for supraglacial lake depth from OLI data. We use in situ spectral measurements from a supraglacial lake in Greenland to emulate satellite reflectance and compare them with depth data from the same lake to test several techniques to extract lake depth. We then apply the best methods to OLI imagery for case study areas in northwestern Greenland and the Sermeq Kujalleq (Jakobshavn Isbræ) area. We validate depth estimates using digital elevation models (DEMs) derived from stereo submeter imagery. We discuss best practices for deriving lake depths using OLI and the implications of these conclusions for other multispectral sensors. Analysis of 2014 imagery yields information about supraglacial lake size, distribution, and seasonal behavior.

\section{Methods}

\subsection{Physically based lake depth}

The depth of a supraglacial lake can be approximated as (after Philpot, 1989)

$z=\left[\ln \left(A_{d}-R_{\infty}\right)-\ln \left(R_{\text {lake }}-R_{\infty}\right)\right] / g$,

where $z$ is lake depth in meters, $A_{d}$ is the lake bottom albedo, $R_{\infty}$ is the reflectance of optically deep water, $R_{\text {lake }}$ is the reflectance of a lake pixel, and $g$ is related to the losses in upward and downward travel through the water column (units: $\mathrm{m}^{-1}$ ). Based upon a description of the processes that take place as light enters, passes through, and exits a lake, this method has been used successfully in both Greenland and Antarctica (e.g., Banwell et al., 2014; Sneed and Hamilton, 2007). It is physically based and therefore easy to adjust when measurements of lake water and lake bed properties are available. However, this method assumes that lake water has little to no dissolved or suspended matter and would be severely impacted by surface waves (wind-driven ripples, choppy waves, etc.). Additionally, it requires that the lake bottoms have low slopes and a homogeneous albedo (Sneed and Hamilton, 2011). While most of these assumptions hold for supraglacial lakes in Greenland (Sneed and Hamilton, 2011), lake bottoms are known to be too inhomogeneous to support the approach generally. In addition, optically deep water (i.e., deep lakes or ocean where the upwelling radiance originates from the water column without any bottom signal contribution) is not always available in inland Landsat scenes. The effects of these shortcomings on supraglacial lake depth retrievals have not been quantified.

In this study, for application to OLI imagery, $R_{\infty}$ was obtained from dark ocean or lake water in the scene, following Sneed and Hamilton $(2007,2011)$. If no coast was available in the scene containing the lake, $R_{\infty}$ was obtained from another scene further along the path (with an implicit assumption of similar atmospheric conditions). The parameter $g$ was calculated following earlier studies (Smith and Baker, 1981; Sneed and Hamilton, 2007) but with an updated absorption coefficient from Pope and Fry (1997, Table 3); for more details, see the Supplement.

$A_{d}$ was obtained from the reflectance immediately outside identified lake areas. However, in order to test this approximation for $A_{d}$, we also solve for lake bottom albedo rather than assuming it to be the same as the surrounding ice. We use spectral mixture analysis (Lillesand et al., 2007) to define a fractional coverage of ice $\left(r_{\mathrm{i}}\right)$ and cryoconite $\left(r_{\mathrm{c}}=1-r_{\mathrm{i}}\right)$ in each lake bottom pixel. To create a determinable equation 
after introducing this new unknown $\left(r_{\mathrm{i}}\right)$, we use reflectances from two OLI spectral bands (indicated with subscripts 1 and 2 , below) and derive end-member reflectances for ice $\left(R_{\mathrm{i} 1}\right.$ or $\left.R_{\mathrm{i} 2}\right)$ and cryoconite $\left(R_{\mathrm{c} 1}\right.$ or $\left.R_{\mathrm{c} 2}\right)$ using glacier reflectance spectra from Pope and Rees (2014b) in conjunction with OLI spectral response functions in both bands (Barsi et al., 2014). We input these parameters into Eq. (1) and then combine the expressions by equating lake depth, thus obtaining

$\left[\frac{r_{\mathrm{i}}\left(R_{\mathrm{i} 1}-R_{\mathrm{c} 1}\right)+R_{\mathrm{c} 1}-R_{\infty 1}}{R_{w 1}-R_{\infty 1}}\right]^{g_{2}}=\left[\frac{r_{\mathrm{i}}\left(R_{\mathrm{i} 2}-R_{\mathrm{c} 2}\right)+R_{\mathrm{c} 2}-R_{\infty 2}}{R_{w 2}-R_{\infty 2}}\right]^{g_{1}}$.

After Eq. (2) is solved for $r_{\mathrm{i}}$, the bottom albedo for one OLI spectral band can be calculated and subsequently used to compute lake depth:

$A_{d 1}=r_{\mathrm{i}} R_{i 1}+\left(1-r_{\mathrm{i}}\right) R_{\mathrm{c} 1}$

$z=\frac{\log \left(R_{\text {lake1 }}-R_{\infty 1}\right)-\log \left(A_{d 1}-R_{\infty 1}\right)}{-g_{1}}$,

where $R_{\text {lake1 }}$ is water leaving reflectance (as in Eq. 1) for the first band in the pair used and $z$ is lake depth.

\subsection{Empirically derived lake depth}

The second method we consider uses spectral band ratios to derive water depth. It has been used in shallow marine settings (e.g., Dierssen et al., 2003) and alluvial rivers (e.g., Legleiter and Overstreet, 2012) and has been adapted for use on the Greenland Ice Sheet (Legleiter et al., 2014). While the physically based method above is highly dependent on $A_{d}$ and $g$, earlier studies show that the spectral band-ratio method is expected to be more robust to variations in these parameters (Legleiter et al., 2009; Stumpf et al., 2003). This is because the method relies on relative behavior in two different wavelengths, as opposed to absolute optical behavior.

This spectral band-ratio method employs an empirically derived quadratic formula to relate lake depths to the ratio of the reflectance of two spectral bands $\left(R_{1}\right.$ and $\left.R_{2}\right)$ :

$z=a+b X+c X^{2}$,

$X=\ln \left(R_{1} / R_{2}\right)$.

This empirical method requires the derivation of calibrated coefficients (i.e., $a, b$, and $c$ ), and coefficients vary depending on which sensors and bands are used (Legleiter et al., 2014). We calculate these coefficients using a known set of reflectances and depths (from in situ measurements, see Sects. 3.1 and 4.1).

\section{Data}

We use three data sets in this study: in situ reflectance spectra and lake depth, OLI imagery, and DEMs derived from stereo WorldView imagery. We use in situ data to test different lake retrieval methods for a range of spectral bands. Then, we calculate lake depth with a range of the most promising methods using OLI imagery. We then use WorldView DEMs to validate the OLI-derived lake depths. The detailed workflow of software (including MATLAB and shell scripts that call GDAL utilities) used for data analysis and presentation in this study will be fully described and documented in a subsequent paper (Pope, 2016).

\subsection{In situ data}

In summer 2010, Tedesco and Steiner (2011) used a small remote-controlled boat equipped with a compact spectroradiometer and a small sonar to collect coincident lakebottom reflectance and depth over one lake in West Greenland (Tedesco et al., 2015). We use 2226 unique sample points from that study to evaluate the performance of the remote sensing methods described above. Field spectra are convolved to account for the spectral response of the spaceborne sensors as follows:

$r_{\mathrm{nb}}=\frac{\int_{0}^{\infty} r(\lambda) R(\lambda) \mathrm{d} \lambda}{\int_{0}^{\infty} R(\lambda) \mathrm{d} \lambda}$,

where $r_{\mathrm{nb}}$ is the narrowband reflectance, $r(\lambda)$ is the spectral reflectance, $R(\lambda)$ is the relative spectral response (Barsi et al., 2014), and $\lambda$ is the wavelength. In order to emulate sensor dynamic range and radiometric resolution, we impose minimum and maximum reflectances and round reflectance values to the appropriate precision (i.e., 8 or 12 bit; see Pope and Rees, 2014a). We then regress the convolved reflectances and in situ depth measurements to test the goodness of fit of the physically based relationship presented in Eq. (1) and the empirical method described in Eqs.(5) and (6).

\subsection{OLI imagery}

Landsat 8 launched on 11 February 2013 and became operational on 30 May 2013 (Roy et al., 2014). OLI collects spectral data gridded at $30 \mathrm{~m}$ spatial resolution $(15 \mathrm{~m}$ for panchromatic data). We calculate top-of-atmosphere (TOA) reflectance using calibration coefficients provided in the image metadata and a solar elevation cosine correction (USGS, 2013). Based on a sensitivity analysis of path radiance to water vapor and ozone using an atmospheric radiative transfer model (see Sect. 5), we do not atmospherically correct the images.

We choose two study areas for applying OLI imagery (see Fig. 1). One site located in northwestern Greenland (including Sverdrup Gletsjer, Dietrichson Gletsjer, Sermersuaq, and Kjer Gletsjer, on Melville Bay; 56.2966-58.7186 W, $74.9685-75.7808^{\circ} \mathrm{N}$ ) is an area with a high concentration of lakes and was imaged four times by OLI throughout summer 2013. A larger region farther to the south is examined using all available OLI scenes collected over the Sermeq Kujalleq 


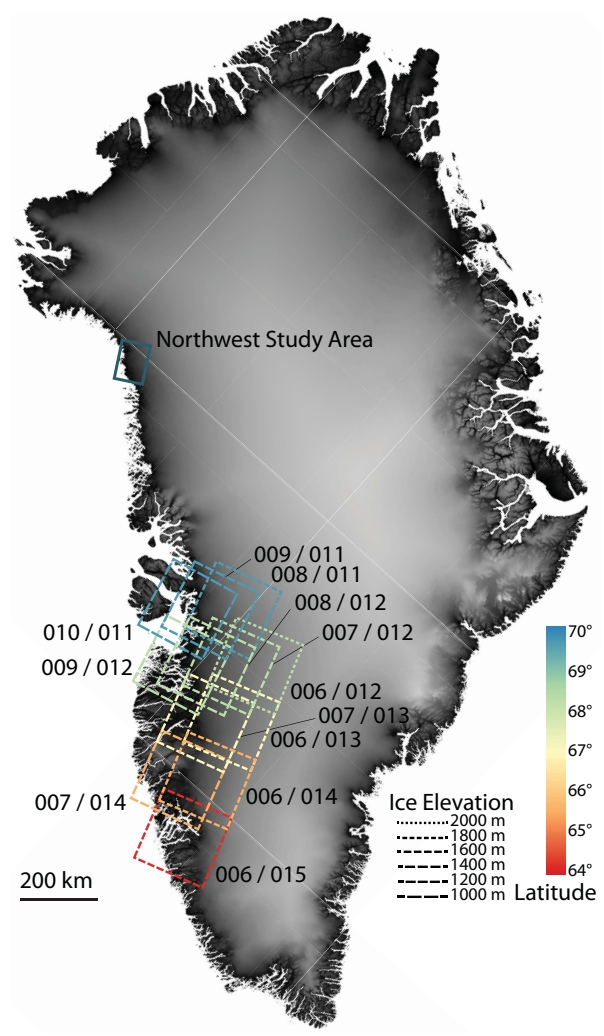

Figure 1. Regional map showing the two study regions for lake depth estimation using OLI imagery. The northwestern Greenland study region is identified with a single box indicating a subscene area. The Sermeq Kujalleq study region shows WRS-2 path/row outlines for Landsat scenes color-coded and dashed to indicate the mean latitude and average elevation of ice within the scenes (see Sect. 4.4 and Table S2). The background is elevation from the Greenland Ice Mapping Project (GIMP) DEM (Howat et al., 2014, 2015).

region in West Greenland in 2014. For a list of all OLI scenes used in this study, see Table S2 in the Supplement.

Using the calculated TOA reflectances, we define supraglacial lake extent using the ratio between the blue and red bands (Banwell et al., 2014; Box and Ski, 2007). However, since OLI bands are slightly different from those of past sensors, we could not use published thresholds for extent. We set the threshold for this ratio at 1.5 (versus 1.05-1.25 for ETM+ in Banwell et al., 2014) based upon visual comparison with the imagery. We then visually inspected and manually adjusted the threshold mask to remove coastal water areas (i.e., not on the ice sheet) and clouds. Although Leeson et al. (2013) describe such thresholding as too coarse for low-resolution imagery (i.e., MODIS), they do acknowledge its utility for higher-resolution imagery (ASTER, Landsat, etc.). We remove regions four pixels or smaller (i.e., small lakes likely comprised solely of mixed pixels) or less than two pixels wide (i.e., linear features likely to be channels, not lakes) from the lake mask.
We interpolate the lake mask using a nearest neighbor algorithm in order to apply the physically based method to the higher-resolution panchromatic band. Where both panchromatic and spectral bands were used together, we bilinearly interpolate the panchromatic image to $30 \mathrm{~m}$ resolution.

\subsection{WorldView DEMs}

We use submeter $\left(\sim 0.5 \mathrm{mpixel}^{-1}\right)$ stereo imagery from WorldView-1 and WorldView-2 to create DEMs of lake areas both before filling and after drainage. Similar validation for ASTER has been carried out with airborne LiDAR from before lake drainage (Georgiou et al., 2009) and for estimating lake drainage volumes (Stevens et al., 2015). We generate the high-resolution WorldView DEMs using the opensource NASA Ames Stereo Pipeline tool (Moratto et al., 2010; Shean et al., 2016). For both the Sermeq Kujalleq and northwestern sites, we use DEMs from 6 different days, for a total of 12 DEMs (see Table S2).

WorldView-1 image data have a geolocation accuracy of better than $4.0 \mathrm{~m}$ horizontal $90 \%$ circular error of probability and WorldView-2 better than $3.5 \mathrm{~m}$ (DigitalGlobe, 2014). Thus, the imagery and DEMs are more precisely positioned than the 15-30 $\mathrm{m}$ OLI.

The vertical accuracy of the derived DEM products is less than $5.0 \mathrm{~m} 90 \%$ vertical error of probability with submeter relative vertical precision (Mitchell, 2010). Differencing a WorldView DEM with an Airborne Topographic Mapper LiDAR profile over a pronounced basin in northeastern Greenland provided a standard deviation over the spread of elevations of $0.25 \mathrm{~m}$. Considered conservatively, differencing one WorldView DEM with a second DEM collected 1 year later provided a standard deviation of $0.58 \mathrm{~m}$ for the elevation differences (Willis et al., 2015). Stacks of 13 and 17 overlapping WorldView-1 and WorldView-2 DEMs over Summit Station and Tracy Glacier, Greenland, provide absolute vertical accuracy estimates of $\sim 2.0-3.0 \mathrm{~m}$ relative to airborne LiDAR measurements ( $\sim 10 \mathrm{~cm}$ accuracy). After removing absolute horizontal and vertical offsets from all DEMs, the relative vertical accuracy $(1 \sigma)$ for the stack was $\sim 15-30 \mathrm{~cm}$ (Shean et al., 2016).

We resample the DEMs to the same grid as OLI imagery using cubic interpolation. The OLI and WorldView acquisitions are from different dates; although lake basins do ablate during the summer, this should not have significant impact on the results presented here, because most supraglacial lakes in Greenland remain fixed over bedrock-controlled surface depressions (Lampkin and VanderBerg, 2011). Using the lake mask, we identify a shoreline for a given date (see Sect. 3.2), which is then used to derive lake depth. We remove outliers of impossibly shallow (i.e., negative depth) or deep (> $65 \mathrm{~m}$ ) values as errors in the DEM. In addition, we remove lakes having a standard deviation in lake elevation along the shoreline of larger than $1.5 \mathrm{~m}$. These steps also mitigated any potential bias caused by temporal offset be- 
Table 1. Laboratory-based and in situ derived water absorption coefficients for lake depth estimation using the physically based method ( $g$, see Eq. 1) and empirical method ( $a, b$, and $c$; see Eqs. 5-6). Regression statistics (correlation coefficient and root mean squared error) for lake depth estimates using field spectra convolved to emulate multispectral bands are also included. Asterisks indicate the methods applied to OLI data in this paper. Bold text indicates recommended bands for lake depth estimation with OLI. See Table S1 for results from other multispectral sensors.

\begin{tabular}{|c|c|c|c|c|c|}
\hline Satellite and band & \multicolumn{2}{|c|}{$\begin{array}{c}\text { Lab-based } \\
g\left(\mathrm{~m}^{-1}\right)\end{array}$} & $\begin{array}{r}\text { Regressed } \\
g\left(\mathrm{~m}^{-1}\right)\end{array}$ & $r$ & $\operatorname{RMSE}(\mathrm{m})$ \\
\hline OLI 1 (coastal) & \multicolumn{2}{|c|}{0.0178} & 0.0093 & 0.0494 & 11.03 \\
\hline OLI 2 (blue) & \multicolumn{2}{|c|}{0.0341} & 0.025 & 0.2886 & 3.10 \\
\hline *OLI 3 (green) & \multicolumn{2}{|c|}{0.1413} & 0.01 & 0.7842 & 0.78 \\
\hline *OLI 4 (red) & \multicolumn{2}{|c|}{0.7507} & 0.80 & 0.9624 & 0.28 \\
\hline *OLI 8 (panchromatic) & \multicolumn{2}{|c|}{0.3817} & 0.36 & 0.8422 & 0.63 \\
\hline ETM+ 1 (blue) Gain H & \multicolumn{2}{|c|}{0.0334} & 0.03 & 0.2626 & 3.34 \\
\hline ETM+ 1 (blue) Gain L & \multicolumn{2}{|c|}{0.0334} & 0.03 & 0.2625 & 3.34 \\
\hline ETM+ 2 (green) Gain H & \multicolumn{2}{|c|}{0.1665} & 0.15 & 0.7892 & 0.77 \\
\hline ETM+ 2 (green) Gain L & \multicolumn{2}{|c|}{0.1665} & 0.14 & 0.7890 & 0.77 \\
\hline ETM+ 3 (red) Gain H & \multicolumn{2}{|c|}{0.8049} & 0.83 & 0.9548 & 0.31 \\
\hline ETM+ 3 (red) Gain L & \multicolumn{2}{|c|}{0.8049} & 0.83 & 0.9412 & 0.37 \\
\hline OLI 1 and 2 (coastal and blue) & \multicolumn{2}{|c|}{-} & - & 0.7871 & 2.57 \\
\hline OLI 1 and 3 (coastal and green) & \multicolumn{2}{|c|}{ - } & - & 0.9208 & 1.10 \\
\hline OLI 1 and 4 (coastal and red) & \multicolumn{2}{|c|}{-} & - & 0.8987 & 1.34 \\
\hline OLI 2 and 3 (blue and green) & \multicolumn{2}{|c|}{-} & - & 0.9401 & 0.88 \\
\hline OLI 2 and 3 (blue and red) & \multicolumn{2}{|c|}{-} & - & 0.8885 & 1.41 \\
\hline OLI 3 and 4 (green and red) & \multicolumn{2}{|c|}{-} & & 0.6063 & 1.74 \\
\hline Satellite and bands & $a$ & $b$ & $c$ & $r$ & $\operatorname{RMSE}(\mathrm{m})$ \\
\hline OLI 3 and 4 (green and red) & -13.8398 & 40.0344 & -23.4057 & 0.4537 & 0.89 \\
\hline OLI 2 and 4 (blue and red) & 3.4414 & -9.0500 & 7.8243 & 0.8610 & 0.51 \\
\hline OLI 1 and 2 (coastal and blue) & 0.9750 & 18.1837 & 145.7811 & 0.8031 & 0.59 \\
\hline OLI 1 and 3 (coastal and green) & 0.1488 & 5.0370 & 5.0473 & 0.9228 & 0.38 \\
\hline OLI 1 and 4 (coastal and red) & 4.8374 & -11.2317 & 8.2001 & 0.8964 & 0.44 \\
\hline OLI 1 and 8 (coastal and pan) & 1.6240 & -5.9696 & 12.4983 & 0.9473 & 0.32 \\
\hline ETM+ 2 and 3 (green and red) L & 1.4794 & -3.2173 & 2.8860 & 0.8855 & 0.46 \\
\hline ETM+ 2 and 3 (green and red) $\mathrm{H}$ & 2.3102 & -4.4616 & 3.2802 & 0.8970 & 0.44 \\
\hline ETM+ 1 and 3 (blue and red) L & 4.0925 & -5.3290 & 2.4296 & 0.9655 & 0.26 \\
\hline $\mathrm{ETM}+1$ and 3 (blue and red) $\mathrm{H}$ & 4.2825 & -5.4754 & 2.4225 & 0.9694 & 0.24 \\
\hline
\end{tabular}

tween DEM and spectral depth measurements. After filtering, over 250000 pixels $(30 \mathrm{~m})$ in total remained for spectral lake depth validation over 6 days in 2013 and 6 days in 2014 .

\section{Results}

\subsection{In situ results}

The results (Table 1) of depth-reflectance regressions for all methods are shown in Fig. 2. We base the bands tested here using in situ data upon those identified in the literature (e.g., Box and Ski, 2007; Sneed and Hamilton, 2007; Tedesco and Steiner, 2011), as well as the OLI's new coastal band and the significantly narrowed panchromatic band $(0.500-$ $0.680 \mu \mathrm{m}$, at $15 \mathrm{~m}$ spatial resolution). ETM+ high and low gain results are virtually indistinguishable, and so only low gain results are shown here. For each regression, we use the correlation coefficient $(r)$ and the root mean square error (RMSE, relative to sonar depths) to assess the performance of each method. The results of the physically based method show that the OLI blue and coastal bands do not perform well relative to other bands (RMSE of 3.10 and $11.03 \mathrm{~m}$, respectively; $r$ of 0.29 and 0.05 , respectively). The OLI Band 3 (green, 0.525-0.600 $\mu \mathrm{m} ; 0.78 \mathrm{~m}, r=0.78$ ) performs as well as legacy ETM+'s Band 2 (green, 0.525-0.605 $\mu \mathrm{m}$; $0.77 \mathrm{~m}, r=0.79$ ). Finally, both OLI Band 4 (red, 0.640$0.670 \mu \mathrm{m})$ and Band 8 (panchromatic, $0.500-0.680 \mu \mathrm{m}$ ) outperform their analogous ETM+ bands (RMSE of 0.28 and $0.63 \mathrm{~m}$, respectively; $r$ of 0.96 and 0.84 , respectively).

Red light attenuates more strongly in water than green or blue light. So, for the same lake depth, there will be a larger (and easier to measure) change in net reflectance for red wavelengths than shorter wavelengths. However, the rapid at- 

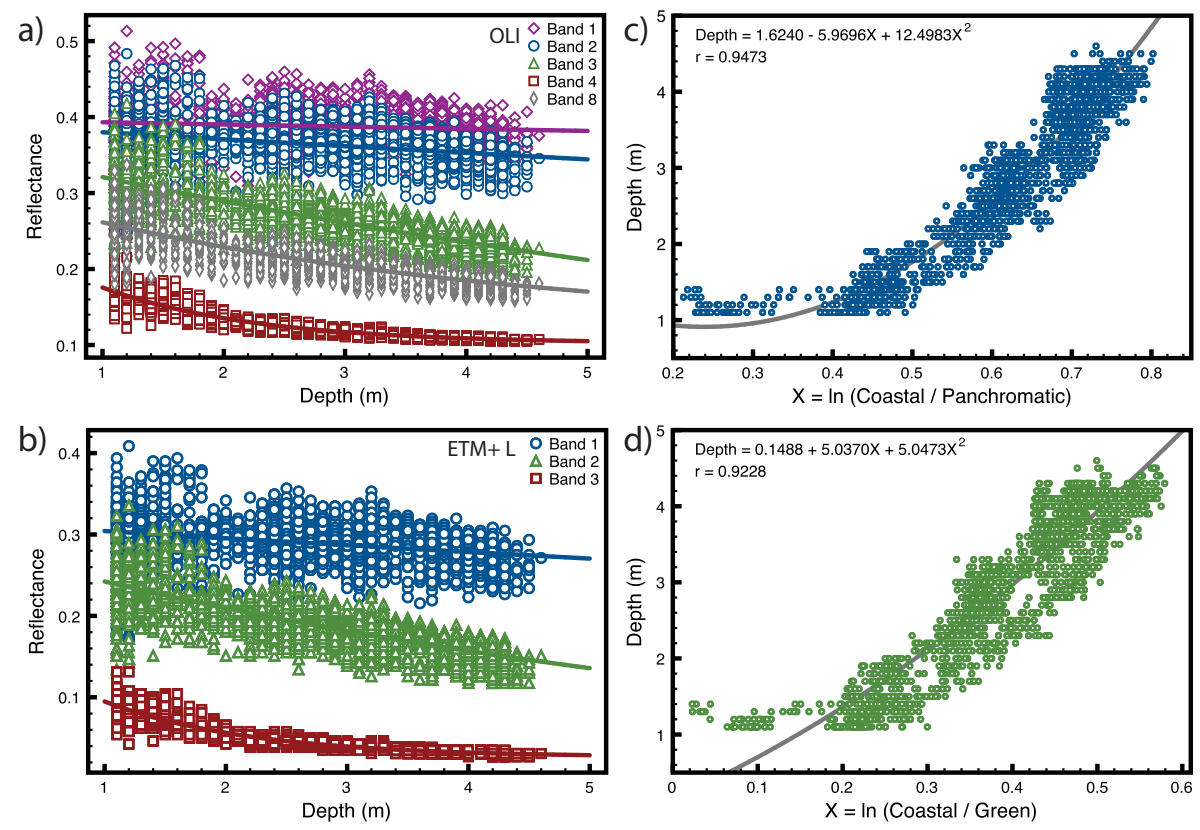

Figure 2. Regression plots for in situ measured reflectance spectra used to emulate OLI and ETM+ reflectance and sonar-measured depths, including OLI single band (a), ETM+ low gain single band (b), OLI coastal and panchromatic (c), and OLI coastal and green (d). Statistics for all regressions are reported in Table 1 .

tenuation of red light means that only shallower lakes may be measured in this band. The maximum in situ lake depth measurement is $\sim 5 \mathrm{~m}$, well within the red light limit, but deeper lakes may exist in the overall study area. We address this issue below by using many Landsat scenes and WorldView DEMs.

We investigate the two-band physically based method (where $A_{d}$ was calculated) with a range of emulated OLI bands (see Table 1). We find similarly high correlation coefficients $(r=0.94)$ to the regression method. Nevertheless, only the combination of blue and green bands had an RMSE below $1 \mathrm{~m}$. This method appears to slightly overestimate lake depths. We investigate the reasons for this with the OLI and WorldView data below.

Applying the empirical method using field data (see Table 1, Fig. 2) indicates that the more continuous bands of the ETM+ outperform the narrower (less spectrally autocorrelated) bands of the OLI when estimating lake depths. However, the addition of the coastal band should allow the OLI still to perform quite well $(r>0.92$, RMSE $<0.38)$, in particular when paired with the green or panchromatic bands.

Our analysis shows that supraglacial lake depth retrievals using OLI are as good as or better than ETM+ retrievals. We identify the best methods for OLI (identified with asterisks in Table 1) based on the highest correlation coefficients and lowest RMSEs. We then apply these methods to OLI data and validate them with WorldView stereo DEMs.

\subsection{3 northwestern Greenland results}

In the northwestern Greenland study area, we identified 694 lakes on 2 July 2013 with a total area of $27.2 \mathrm{~km}^{2}, 1259$ lakes totaling $43.7 \mathrm{~km}^{2}$ on 18 July 2013, 955 lakes totaling $38.8 \mathrm{~km}^{2}$ on 3 August 2013, and 274 lakes totaling $8.6 \mathrm{~km}^{2}$ on 19 August 2013. We calculate lake depths with all previously discussed methods, as well as an average between the two best single-band depth estimates. Total lake volume in the study area increased in early July, stayed almost constant as lake growth areas moved higher in elevation over the following three weeks, and then decreased again toward the end of August as cooler conditions prevailed (see Fig. 3). While all methods show the same pattern of surface water storage, the total water volumes derived with the different methods differ by over a factor of 2 .

\subsection{Comparison with DEMs}

For both of our case study regions, northwestern and southwestern Greenland, we difference all overlapping areas of OLI-derived lake depths and WorldView-derived DEMs. The statistics of this comparison are shown in Fig. 4. As seen in the northwestern Greenland case study, the results are divided into two groups. OLI-derived depths using Band 3, Bands 2 and 3, a ratio of Bands 1 and 3, and a ratio of Bands 1 and 8 all considerably overestimate lake depth relative to the DEMs. However, the physically based singleband method for the red band (OLI Band 4) only slightly underestimates lake depth $(-0.1 \pm 1.7 \mathrm{~m})$, while the panchro- 


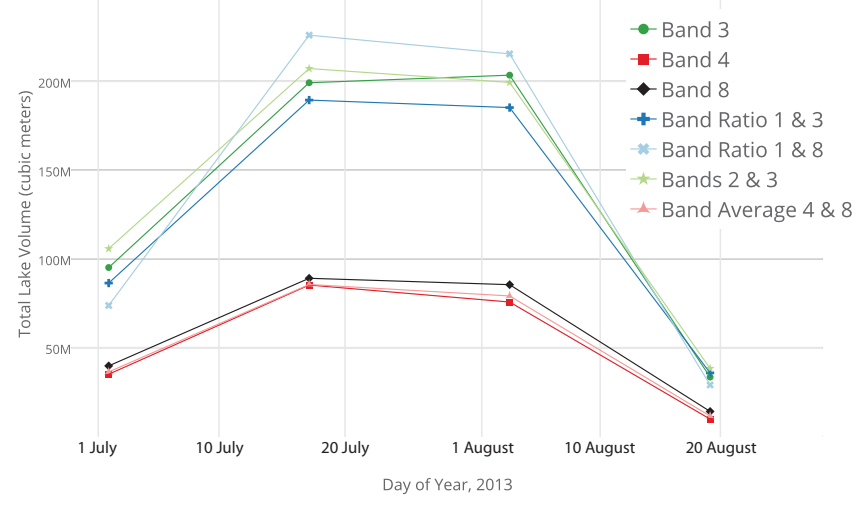

Figure 3. Total water volume stored in supraglacial lakes in the northwestern Greenland study region for the summer of 2014 derived using OLI. Based on analysis, "Band Average 4 and 8" is likely to be the most accurate (see Fig. 4).

matic band (OLI Band 8) slightly overestimates lake depth $(0.1 \pm 1.4 \mathrm{~m})$.

Combining these two best-performing bands, the resulting spectral and DEM-derived lake depths are in close agreement, showing a difference of $0.0 \pm 1.6 \mathrm{~m}$. We infer that the optimal method for estimating supraglacial lake depth with OLI is to take an average of the physically based (see Eq. 1) depths as derived from the red and panchromatic channels (bold in Table 1). It is likely that the spread in depths is the result of a combination of factors including temporal offset between DEM and spectral data collection, image coregistration, and atmospheric effects, as well as uncertainties inherent in the lake depth retrievals. Despite meter-scale uncertainties $(1.6 \mathrm{~m})$ at the pixel level, the mean lake depth derived from these methods agrees well.

\subsection{Sermeq Kujalleq area results}

We apply the lake depth algorithm (i.e., average of singleband depths from OLI red and panchromatic bands) to 34 OLI images from the summer of 2014 over the Sermeq Kujalleq area (see Figs. 1 and 5). The total meltwater storage in supraglacial lakes peaked near $3 \mathrm{~km}^{3}$ across the entire study area in mid-July 2014 . There are many shallow lakes ( 0.3 to $1.5 \mathrm{~m}$ depth) and many lakes with depths of 2.5 to $4 \mathrm{~m}$. Few lakes exceed $5.5 \mathrm{~m}$ depth (see Fig. 6a). The preponderance of shallow lake pixels reflects the fact that the observed lakes have low surface slopes at their edges.

If the water stored in supraglacial lakes in row 12 of path 008 in mid-July were spread across the whole $25246 \mathrm{~km}^{2}$ of ice in the scene, it would have an average depth of almost $3 \mathrm{~cm}$. In other scenes, calculations provide average depths of 0.5 to $1.5 \mathrm{~cm}$. Our maximum observed value is almost as high as the volume in supraglacial streams measured by Smith et al. (2015), reinforcing the potentially daily turnover of a well-connected surface system they observed. Indeed,

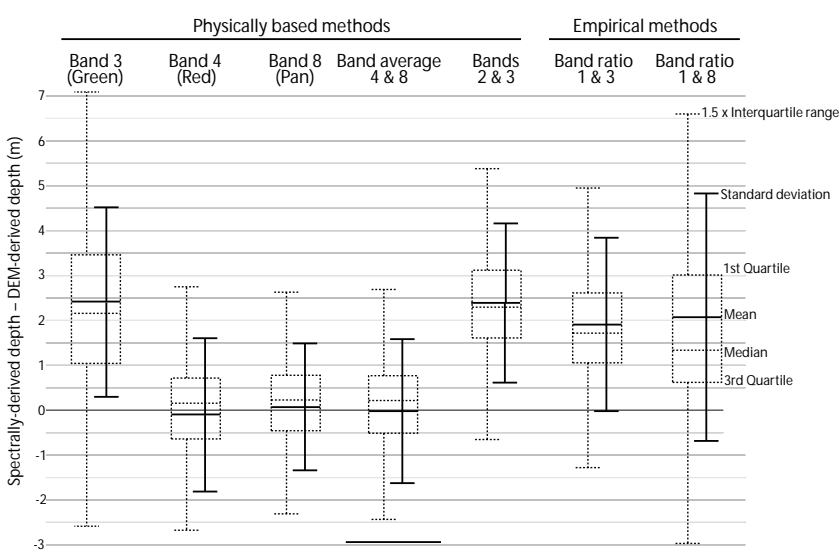

Figure 4. Statistics for the difference in supraglacial lake depth from physically based and empirical methods derived from OLI imagery and WorldView DEMs, including mean/standard deviation (solid lines) and median/quartiles (dotted lines). An average of the Band 4 and Band 8 methods is used for our mapping (Figs. 5 and 6). The method showing the least bias and lowest errors is an average of Band 4 (red) and Band 8 (panchromatic) single-band physically based retrievals, with a mean offset of $0.0 \pm 1.6 \mathrm{~m}$ (as indicated by the bar at the bottom of the diagram). Discrepancies in lake depth estimation for physically based retrievals can be traced to differences between lab-measured and in situ regressed water absorption coefficients (see Table 1).

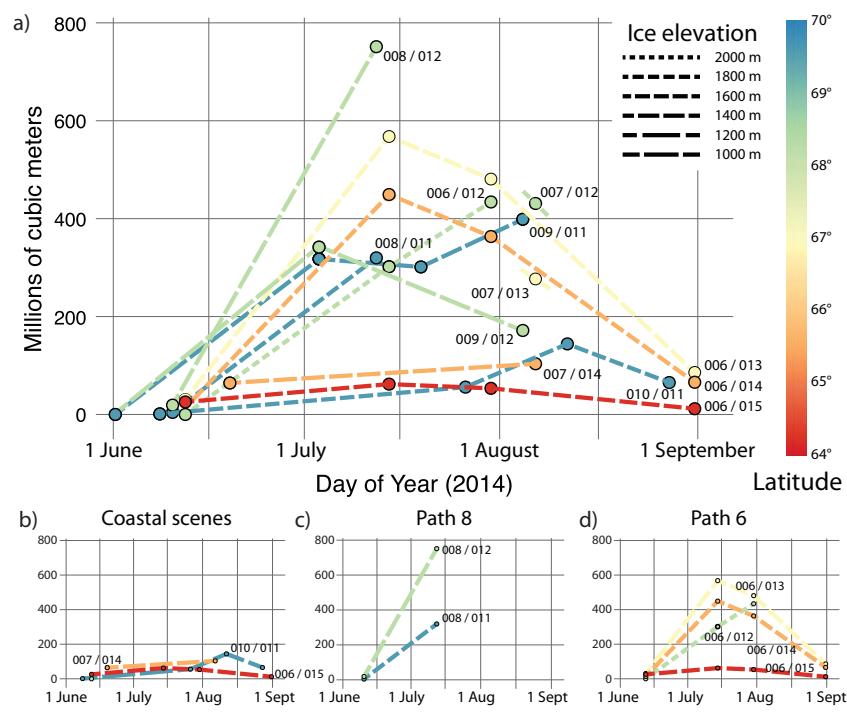

Figure 5. Total water stored in supraglacial lakes over the 2014 summer using single Landsat 8 scenes (as indicated by WRS-2 path/row annotations) covering the Sermeq Kujalleq region (see Fig. 1, Table S1). All scenes are shown together in (a). (b) shows only the low-elevation coastal scenes, demonstrating delayed lake formation at higher latitudes. (c) shows both elevation and latitude effects in driving supraglacial water storage for scenes in WRS-2 path 8. (d) shows latitude and elevation effects for scenes in WRS-2 path 6. All sub-figures are on the same grid as part (a). 
Tedesco et al. (2012) observe bare ice melt rates next to supraglacial lakes in West Greenland of $\sim 2.5-3 \mathrm{~cm} \mathrm{day}^{-1}$, similar to those observed by van den Broeke et al. (2011). This implies that lakes are storing on the order of 1 day's worth of melt (or less), indicating daily or subdaily residence times, depending on connectivity.

The Sermeq Kujalleq data set also provides a time series that shows lake growth and drainage/freezing (see Fig. 5a). There are many factors that contribute to lake growth and drainage, including temperature, insolation, albedo, topography, and ice dynamics. These complex drivers are related to the more easily quantified mean elevation and latitude of each scene. For example, isolating the coastal scenes shows the delayed onset of melt and earlier shutdown in the north compared to the south (see Fig. 5b).

To further refine our investigation of geographic factors associated with lake depth over the summer season, we examine single swaths of OLI imagery through time. Path 008 (in the WRS-2 reference scheme; Irons et al., 2012), which transects the lower Sermeq Kujalleq, shows a strong influence both of elevation and latitude in rates of lake growth and water storage (Fig. 5c). Isolating Path 006, however, conflates the effects of elevation and latitude on surface meltwater storage, but because we have more temporal coverage (see Fig. 5d) we see the decline of total lake volume as summer progresses toward autumn. Again, higher latitude and elevation delay melt onset (i.e., Path 006, Row 012). For 006/013 and $006 / 014$, it is likely that the reduced ice sheet area within $006 / 014$ is the explanation for the reduced meltwater volume. Rates of increase and decay of lake volume are similar for this pair.

The distribution of lake depths (by pixel) with elevation is shown in Fig. 6b. Lakes are distributed from $\sim 300$ to $\sim 2100 \mathrm{~m}$ elevation. Maximum lake depths occur at about $1200 \mathrm{~m}$ a.s.l. At lower elevations, lake depths recorded by our method vary significantly, likely due to rapid lake growth and drainage across a range of dates at lower elevations, versus the higher elevation maximum depths mostly derived from an OLI image on 30 July 2014. From 1200 to $2100 \mathrm{~m}$, measured lake depths decline steadily with less variation. This likely reflects a combination of factors, including the variations in induced surface topography of the ice sheet as it flows over undulating bedrock (Lampkin and VanderBerg, 2011). At higher elevations, slow flow leads to low-amplitude ice surface topography thus shallower depressions, and there is also less available meltwater to fill ice-surface depressions. In addition, while lakes are less likely to variably fill and drain at higher elevations, there was also reduced imagery available from $\sim 30$ July 2014 onwards. Therefore, the more consistent maximum depths at higher elevations are a combination of incomplete temporal coverage and elevation. Further down, more melt and higher amplitude topography from faster ice flow facilitate lake formation. However, below $1200 \mathrm{~m}$, increased ablation begins to reduce this topography. In addition, the volume of melt available will determine whether depressions are large enough to hold lakes or instead drain via connecting supraglacial channels. The melt volume and therefore the relationship between lakes and channels will thus vary both seasonally and with elevation (Lampkin and VanderBerg, 2014).

\section{Discussion}

\subsection{Retrieval performance factors}

The depths returned by the empirical (band-ratio) method considerably overestimate lake depths relative to the WorldView DEMs. The method is entirely dependent upon the calibration of the input parameters (i.e., $a, b$, and $c$ ). The parameters used in this study are in turn based solely upon extrapolation from in situ measurements at a single lake. Therefore, it is possible that the lake used for calibration is not representative of lakes in our study region. Legleiter et al. (2014) note that the coefficients for the empirical method may be scale dependent, and values calculated from field data may not be appropriate for the $30 \mathrm{~m}$ OLI pixels. Indeed, other work (Moussavi et al., 2016) both calibrates and validates spectrally derived depths with WorldView DEMs to show that the band-ratio/empirical method and single-band/physically based method perform similarly well. The use of a ratio of coastal and green reflectances performed well for lake depth retrieval using WorldView-2 imagery (Legleiter et al., 2014). Therefore the band-ratio method may, with better parameters, produce results consistent with the physically based single-band approaches.

The physically based depth retrievals show a large spread in total water volume returns. Physically based depth retrievals rely on accurate bottom albedos $\left(A_{d}\right)$ and water absorption coefficient $(g)$. While $A_{d}$ is derived from the imagery, $g$ is always calculated for each spectral band based on laboratory measurements and is therefore consistent across all OLI scenes. Comparison of laboratory-measured $g$ with those derived from in situ data (see Table 1) shows that when the laboratory-measured $g$ is higher than that obtained from regressing in situ data, lake depths are overestimated and vice versa. For example, OLI Band 3 (green) shows a $70 \%$ difference in directly measured and regressed $g$, and it overestimates lake depths by a mean of $2.4 \pm 2.1 \mathrm{~m}$ relative to WorldView DEMs. By contrast, Band 4 (red) and Band 8 (panchromatic) have very small differences between measured and regressed $g(-0.06$ and $0.06 \%$, respectively) and yield accurate lake depth estimates $(-0.1 \pm 1.7 \mathrm{~m}$ and $0.1 \pm 1.4 \mathrm{~m}$, respectively) relative to WorldView DEMs.

Water absorption properties also vary with wavelength. For example, poor performance in blue and coastal bands is related to very low absorption. Red wavelengths attenuate relatively quickly in water, and this is described by a relatively high $g\left(0.7507 \mathrm{~m}^{-1}\right)$ compared to green $\left(0.1413 \mathrm{~m}^{-1}\right)$. This high $g$ for red light makes it less sensitive to errors in $g$ than green wavelengths. Lake depth estimates using a red 

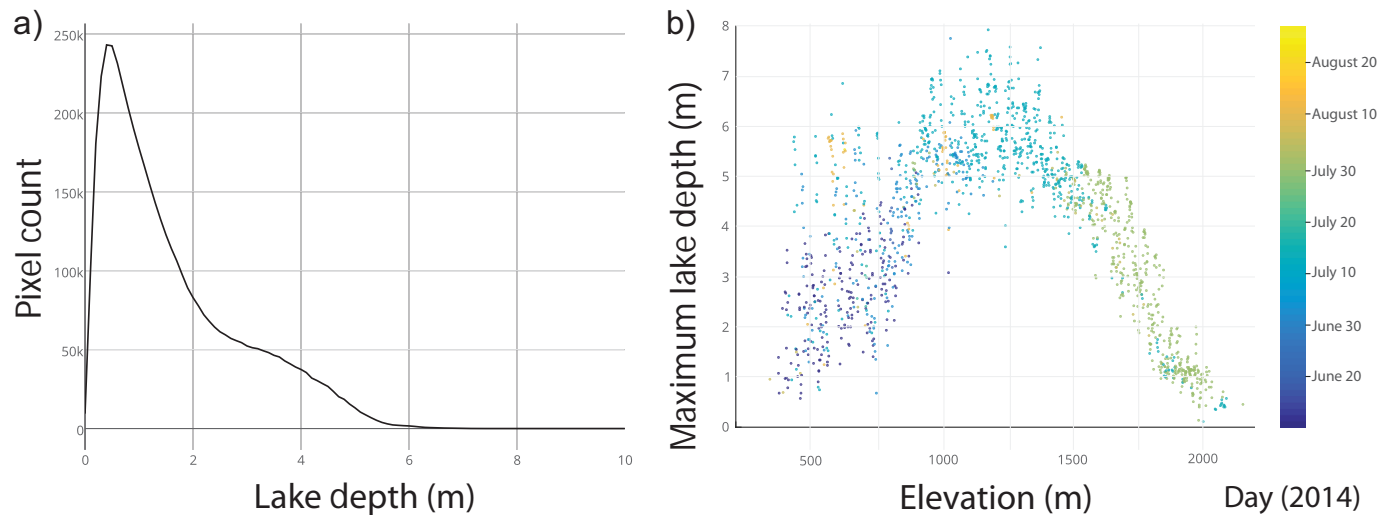

Figure 6. Statistics of lake depth and elevation distribution for all Sermeq Kujalleq region 2014 OLI imagery (see Table S2). (a) Histogram of lake depths. (b) Maximum lake depth in $1 \mathrm{~m}$ elevation bins as derived from the GIMP DEM (Howat et al., 2014, 2015).

channel are also less sensitive to $A_{d}$ than with a green channel (Tedesco and Steiner, 2011), again due to the high absorption for longer wavelengths. Ultimately, as long as the sensor radiometry is able to measure the return from deepwater pixels, longer wavelengths (i.e., red) can return generally more accurate lake depths because they are less sensitive to the input parameters.

\subsection{Revisiting lake depth retrievals}

To evaluate other studies in the literature and compare them with our results, we apply the same methods we use (i.e., labmeasured absorption/scattering parameters and appropriate spectral response functions) to calculate $g \mathrm{~s}$ for ETM+ bands (see Table 1). Tedesco and Steiner (2011) studied the accuracy of ETM+'s green band for lake depth estimation. They tested different multipliers of the diffuse attenuation coefficient for downwelling light to get the water absorption coefficient $g$. They showed that for ETM+'s green band, sonar and spectral depths correlated better when a larger multiplier was used. This is broadly consistent with the $70 \%$ offset between observed and theoretical values that we observe (Table 1). They also find that this offset "cannot be easily explained, aside from a possible chlorophyll concentration in the water, currently considered to be unlikely". Morriss et al. (2013) used ETM+'s red band and extracted a higher value of $g$ $\left(0.86 \mathrm{~m}^{-1}\right)$; this is very close to the regressed value we observe of $0.83 \mathrm{~m}^{-1}$ (see Table 1), and so we expect their depth estimates to be slightly overestimated.

Banwell et al. (2014) and Arnold et al. (2014) also used ETM+'s green band with a $g$ of $0.1954 \mathrm{~m}^{-1}, \sim 40 \%$ higher than our regressed value of $0.14 \mathrm{~m}^{-1}$, leading to depths overestimated by $\sim 30 \%$. Because the comparisons of Greenland and Antarctic lakes (Banwell et al., 2014) are based on relative depths, their conclusions are likely still valid. Arnold et al. (2014) concluded that their model under-predicted water depths, which could in reality mean that their model is be- having correctly but their validation data (i.e., ETM+ lake depths) were biased.

Using the same process as for Landsat sensors, we calculated $g$ s for ASTER, MODIS, and WorldView-2 bands (see Table S1). Sneed and Hamilton $(2007,2011)$ used ASTER's green band for lake depth estimation $\left(g=0.1180 \mathrm{~m}^{-1}\right)$. This is $\sim 20 \%$ smaller than the regressed value of $0.15 \mathrm{~m}^{-1}$ (see Table S1). They will therefore have likely underestimated lake depth (Sneed and Hamilton, 2007).

For all three studies, the regressed $g \mathrm{~s}$ are much closer to the updated lab-based $g$ s (see Sect. 2.1 and the Supplement) than those used in the studies. Adoption of the new $g$ s presented here in Tables 1 and S1 would therefore likely lead to improved lake depth estimates.

\subsection{Sensitivity analysis}

For all sensors, wavelengths, and input parameters, an important consideration for reflectance-derived lake depth is the atmospheric correction used to prepare the multispectral imagery. All imagery is processed to TOA reflectance, which means that there is some extraneous path radiance remnant in the data. Therefore, TOA values will slightly overestimate the true reflectance. This offset will not be the same between bands and will influence the retrieved lake depths as discussed below.

The single-band physically based model requires that the reflectance of optically deep water be derived for each scene separately. Effectively, this shifts the exponential decay curve of light in lake water but does not change its shape. Therefore, as long as path radiance is assumed to be homogeneous across the $185 \mathrm{~km}$ wide OLI scene, TOA reflectance is sufficient for lake depth estimation. To test this assumption, the MODTRAN radiative transfer model (Berk et al., 2005) was used to simulate path radiance on a day for which OLI data were used in northwestern Greenland (18 July 2013) to investigate variations associated with variable water vapor and ozone across a Landsat scene. According to MODIS 
retrievals (accurate to $30 \mathrm{DU}$; Borbas et al., 2011), ozone variability within a Landsat scene is on the order of approximately $\pm 50 \mathrm{DU}$, which translates to a path radiance of $\pm 1.6 \%$ in the red channel. For lake depth, this can propagate to a $\sim 20 \%$ error in lake depth. Much of this error appears largely random for a given point in time and space. Thus, while it decreases confidence in individual lake depth retrievals, averaged water volume retrieval should not be biased. For water vapor there was a $0.3 \%$ change in path radiance between the minimum and maximum Landsat scene values, making it a small contributor to overall error. Between days, however, path radiance effects due to water vapor may vary by an order of magnitude more.

For the multiple-band methods, the differential change in path radiance has larger effects. Sensitivity tests showed that a $3 \%$ change in path radiance for one or both bands changed water volumes on the order of 10-30\%. Therefore, a more rigorous atmospheric correction is necessary in order to apply multi-band lake depth algorithms. Still, for the study here, because validation is conducted across 12 nonconsecutive days in both spring and autumn, we do not expect atmospheric conditions to bias our conclusions.

There are additional limitations to our method. As discussed above, OLI lake depth estimates (average single-band estimates from red and panchromatic bands) are robust for regional averages but not single pixels. In addition, the threshold used to identify lake extent may need to be adjusted for different regions and scenes (e.g., Banwell et al., 2014; Box and Ski, 2007). Lake depth retrievals are also sensitive to variations in ice albedo, as well as to the presence of ice lids on the surface of supraglacial lakes, which can be common both in early and late summer. Cloud cover and Landsat's 16day revisit time also limit the conclusions that can be drawn from OLI lake depths. Many studies have used daily MODIS data to identify and track supraglacial lakes (e.g., Liang et al., 2012; Selmes et al., 2011; Sundal et al., 2011). Fusing the higher temporal resolution of MODIS (or additional sensors such as ESA's upcoming Sentinel-2) and higher spatial resolution of OLI, along with more in situ calibration and validation data, should lead to unique insights to supraglacial water storage.

\section{Conclusion}

Examination of the evolution of water storage on the surface of ice sheets and glaciers is important for understanding mass balance, dynamics, and heat transport throughout the ice mass. In this study, in situ data were used to test the capability of Landsat 8's Operational Land Imager to estimate supraglacial lake depth. Promising methods were applied to two sets of OLI observations. Patterns of water storage were similar from the two methods, but a factor of 2 difference was calculated for the total water volume. WorldView DEMs were used to assess which of the methods was most accurate. The best method identified for OLI was an average of the depth derived from single-band physically based retrievals of Band 4 (red) and Band 8 (panchromatic); the mean difference between spectrally derived and DEM-derived lake depths is only $0.0 \pm 1.6 \mathrm{~m}$, showing no bias but some spread. Therefore, this method is recommended for future lake depth retrievals with OLI, especially for regional studies. This is the first time supraglacial lake depths have been validated across multiple dates and regions.

Discrepancies between spectrally and DEM-derived depths appear to be explained by differences between labmeasured and in situ derived water absorption coefficients $(g)$. The success of other sensors and bands in deriving supraglacial lake depth can thus be inferred from these $g \mathrm{~s}$. With this insight, multispectral lake depth estimates in the literature were revisited. Lake extent studies can now be expanded to include lake volume with higher confidence. Updated $g \mathrm{~s}$ are provided (see Tables 1 and S1), but further in situ data collection and satellite-based studies are needed to build more robust methods.

The recommended depth retrieval method was applied to all available OLI imagery for summer 2014 for the Sermeq Kujalleq (Jakobshavn) region of West Greenland. Seasonal and regional trends in lake depth (deepening and then shallowing), evolution (proceeding inland/up-glacier and northwards through the summer), and distribution $(\sim 300$ to $\sim 2100$ m a.s.1.) were observed. At most, lakes contain a similar magnitude of water to supraglacial streams, but this may not be true for other parts of Greenland. Both elevation (and, relatedly, accumulation/melt forcing) and surface topography play a role in lake formation and extent, behavior that we expect to be modified but observable in other regions. Further work moving forward will need to contextualize Landsat data with other remote sensing imagery, fieldwork, and model outputs.

\section{The Supplement related to this article is available online at doi:10.5194/tc-10-15-2016-supplement.}

Acknowledgements. A. Pope and T. Scambos were supported by USGS contract G12PC00066. D. Shean was supported by NASA grant NNX12AN36H for this work. An award from the NASA NH Space Grant supported a collaboration visit between A. Pope and M. Willis. WorldView imagery was provided by the Polar Geospatial Center at the University of Minnesota, which is supported by grant ANT-1043681 from the US National Science Foundation. M. Willis was supported by NSF ARC-1111882. We thank the University of North Carolina at Chapel Hill Research Computing group for providing computational resources that have contributed to these research results. Non-commercial software tools used in this study included Plot.ly, ImageJ, and QGIS. Publication of this article was funded by the University of Colorado Boulder Libraries Open Access Fund.

Edited by: R. Bingham 


\section{References}

Arnold, N. S., Banwell, A. F., and Willis, I. C.: High-resolution modelling of the seasonal evolution of surface water storage on the Greenland Ice Sheet, The Cryosphere, 8, 1149-1160, doi:10.5194/tc-8-1149-2014, 2014.

Banwell, A. F., MacAyeal, D. R., and Sergienko, O. V.: Breakup of the Larsen B Ice Shelf triggered by chain reaction drainage of supraglacial lakes, Geophys. Res. Lett., 40, 5872-5876, doi:10.1002/2013GL057694, 2013.

Banwell, A. F., Caballero, M., Arnold, N. S., Glasser, N., Cathles, L. M., and MacAyeal, D. R.: Supraglacial lakes on the Larsen B Ice Shelf, Antarctica, and at Paakitsoq, W. Greenland: a comparative study, Ann. Glaciol., 55, 1-8, 2014.

Barsi, J. A., Lee, K., Kvaran, G., Markham, B. L., and Pedelty, J. A.: The Spectral Response of the Landsat-8 Operational Land Imager, Remote Sens., 6, 10232-10251, doi:10.3390/rs61010232, 2014.

Berk, A., Anderson, G. P., Acharya, P. K., Bernstein, L. S., Muratov, L., Lee, J., Fox, M., Adler-Golden, S. M., Chetwynd, J. H., Hoke, M. L., Lockwood, R. B., Gardner, J. A., Cooley, T. W., Borel, C. C., and Lewis, P. E.: MODTRAN 5: a reformulated atmospheric band model with auxiliary species and practical multiple scattering options: update, edited by: Shen, S. S. and Lewis, P. E., 662-667, 2005.

Borbas, E. E., Seemann, S. W., Kern, A., Moy, L., Li, J., Gumley, L., and Menzel, W. P.: MODIS atmospheric profile retrieval algorithm theoretical basis document, available at: http://modis-atmos.gsfc.nasa.gov/_docs/MOD07_atbd_ v7_April2011.pdf (last access: 25 February 2015), 2011.

Box, J. E. and Ski, K.: Remote sounding of Greenland supraglacial melt lakes: implications for subglacial hydraulics, J. Glaciol., 53, 257-265, 2007.

Chu, V. W.: Greenland ice sheet hydrology A review, Prog. Phys. Geog., 38, 19-54, doi:10.1177/0309133313507075, 2014.

Das, S. B., Joughin, I., Behn, M. D., Howat, I. M., King, M. A., Lizarralde, D., and Bhatia, M. P.: Fracture Propagation to the Base of the Greenland Ice Sheet During Supraglacial Lake Drainage, Science, 320, 778-781, doi:10.1126/science.1153360, 2008.

Dierssen, H. M., Zimmerman, R. C., Leathers, R. A., Downes, T. V., and Davis, C. O.: Ocean color remote sensing of seagrass and bathymetry in the Bahamas Banks by highresolution airborne imagery, Limnol. Oceanogr., 48, 444-455, doi:10.4319/lo.2003.48.1_part_2.0444, 2003.

DigitalGlobe: Geolocation Accuracy of WorldView Products, available at: https://www.digitalglobe.com/sites/default/files/ WorldView_Geolocation_Accuracy.pdf (last access: 22 February 2015), 2014.

Fitzpatrick, A. A. W., Hubbard, A. L., Box, J. E., Quincey, D. J., van As, D., Mikkelsen, A. P. B., Doyle, S. H., Dow, C. F., Hasholt, B., and Jones, G. A.: A decade (2002-2012) of supraglacial lake volume estimates across Russell Glacier, West Greenland, The Cryosphere, 8, 107-121, doi:10.5194/tc-8-107-2014, 2014.

Georgiou, S., Shepherd, A., McMillan, M., and Nienow, P.: Seasonal evolution of supraglacial lake volume from ASTER imagery, Ann. Glaciol., 50, 95-100, 2009.

Glasser, N. and Scambos, T.: A structural glaciological analysis of the 2002 Larsen B ice shelf collapse, J. Glaciol., 54, 3-16, 2008.
Howat, I. M., Negrete, A., and Smith, B. E.: The Greenland Ice Mapping Project (GIMP) land classification and surface elevation data sets, The Cryosphere, 8, 1509-1518, doi:10.5194/tc-81509-2014, 2014.

Howat, I. M., Negrete, A., and Smith, B.: MEaSURES Greenland Ice Mapping Project (GIMP) Digital Elevation Model, Version 1., Boulder Colo. USA NASA Natl. Snow Ice Data Cent. Distrib. Act. Arch. Cent., doi:10.5067/NV34YUIXLP9W, 2015.

Irons, J. R., Dwyer, J. L., and Barsi, J. A.: The next Landsat satellite: The Landsat Data Continuity Mission, Remote Sens. Environ., 122, 11-21, doi:10.1016/j.rse.2011.08.026, 2012.

Johansson, A. M. and Brown, I. A.: Adaptive Classification of Supra-Glacial Lakes on the West Greenland Ice Sheet, IEEE J. Sel. Top. Appl., 6, 1998-2007, doi:10.1109/JSTARS.2012.2233722, 2013.

Joughin, I., Das, S. B., Flowers, G. E., Behn, M. D., Alley, R. B., King, M. A., Smith, B. E., Bamber, J. L., van den Broeke, M. R., and van Angelen, J. H.: Influence of ice-sheet geometry and supraglacial lakes on seasonal ice-flow variability, The Cryosphere, 7, 1185-1192, doi:10.5194/tc-7-1185-2013, 2013.

Koenig, L. S., Lampkin, D. J., Montgomery, L. N., Hamilton, S. L., Turrin, J. B., Joseph, C. A., Moutsafa, S. E., Panzer, B., Casey, K. A., Paden, J. D., Leuschen, C., and Gogineni, P.: Wintertime storage of water in buried supraglacial lakes across the Greenland Ice Sheet, The Cryosphere, 9, 1333-1342, doi:10.5194/tc9-1333-2015, 2015.

Lampkin, D. J. and VanderBerg, J.: A preliminary investigation of the influence of basal and surface topography on supraglacial lake distribution near Jakobshavn Isbrae, western Greenland, Hydrol. Process., 25, 3347-3355, doi:10.1002/hyp.8170, 2011.

Lampkin, D. J. and VanderBerg, J.: Supraglacial melt channel networks in the Jakobshavn Isbræ region during the 2007 melt season, Hydrol. Process., 28, 6038-6053, doi:10.1002/hyp.10085, 2014.

Leeson, A., Shepherd, A., Sundal, A., Johansson, A. M., Selmes, N., Briggs, K. H., Hogg, A. E., and Fettweis, X.: A comparison of supraglacial lake observations derived from MODIS imagery at the western margin of the Greenland ice sheet, J. Glaciol., 59, 1179-1188, 2013.

Leeson, A. A., Shepherd, A., Briggs, K., Howat, I., Fettweis, X., Morlighem, M. and Rignot, E.: Supraglacial lakes on the Greenland ice sheet advance inland under warming climate, Nat. Clim. Change, 5, 51-55, doi:10.1038/nclimate2463, 2015.

Legleiter, C. J. and Overstreet, B. T.: Mapping gravel bed river bathymetry from space, J. Geophys. Res.-Earth, 117, F04024, doi:10.1029/2012JF002539, 2012.

Legleiter, C. J., Roberts, D. A., and Lawrence, R. L.: Spectrally based remote sensing of river bathymetry, Earth Surf. Proc. Land., 34, 1039-1059, doi:10.1002/esp.1787, 2009.

Legleiter, C. J., Tedesco, M., Smith, L. C., Behar, A. E., and Overstreet, B. T.: Mapping the bathymetry of supraglacial lakes and streams on the Greenland ice sheet using field measurements and high-resolution satellite images, The Cryosphere, 8, 215-228, doi:10.5194/tc-8-215-2014, 2014.

Liang, Y.-L., Colgan, W., Lv, Q., Steffen, K., Abdalati, W., Stroeve, J., Gallaher, D., and Bayou, N.: A decadal investigation of supraglacial lakes in West Greenland using a fully automatic detection and tracking algorithm, Remote Sens. Environ., 123, 127-138, doi:10.1016/j.rse.2012.03.020, 2012. 
Lillesand, T., Kiefer, R. W., and Chipman, J.: Remote Sensing and Image Interpretation, 6 Edn., Wiley, Hoboken, NJ, USA, 2007.

Mitchell, G.: PhotoSat WorldView-2 Stereo Satellite DEM Comparison to a LiDAR DEM over the Garlock Fault in Southeast California, DigitalGlobe, Longmont, CO, USA, available at: http://global.digitalglobe.com/sites/default/files/ PhotoSatWV-2StereoSatelliteDEMComparison_0.pdf (last access: 4 April 2015), 2010.

Moratto, Z. M., Broxton, M. J., Beyer, R. A., Lundy, M., and Husmann, K.: Ames Stereo Pipeline, NASA's Open Source Automated Stereogrammetry Software, vol. 41, p. 2364, available at: http://adsabs.harvard.edu/abs/2010LPI....41.2364M (last access: 5 March 2014), 2010.

Morriss, B. F., Hawley, R. L., Chipman, J. W., Andrews, L. C., Catania, G. A., Hoffman, M. J., Lüthi, M. P., and Neumann, T. A.: A ten-year record of supraglacial lake evolution and rapid drainage in West Greenland using an automated processing algorithm for multispectral imagery, The Cryosphere, 7, 1869-1877, doi:10.5194/tc-7-1869-2013, 2013.

Moussavi, M., Abdalati, W., Pope, A., Scambos, T., Tedesco, M., Macferrin, M., and Grigsby, S.: Derivation and validation of supraglacial lake volumes on the Greenland Ice Sheet from highresolution satellite imagery, Remote Sens. Environ., in review, 2016.

Parizek, B. R. and Alley, R. B.: Implications of increased Greenland surface melt under global-warming scenarios: icesheet simulations, Quaternary Sci. Rev., 23, 1013-1027, doi:10.1016/j.quascirev.2003.12.024, 2004.

Phillips, T., Rajaram, H., Colgan, W., Steffen, K., and Abdalati, W.: Evaluation of cryo-hydrologic warming as an explanation for increased ice velocities in the wet snow zone, Sermeq Avannarleq, West Greenland, J. Geophys. Res.-Earth, 118, 12411256, doi:10.1002/jgrf.20079, 2013.

Philpot, W. D.: Bathymetric mapping with passive multispectral imagery, Appl. Optics., 28, 1569-1578, 1989.

Pope, A.: Reproducibly Estimating and Evaluating Supraglacial Lake Depth With Landsat 8 and Other Multispectral Sensors, Earth Space Sci., in review, 2016.

Pope, A. and Rees, W. G.: Impact of spatial, spectral, and radiometric properties of multispectral imagers on glacier surface classification, Remote Sens. Environ., 141, 1-13, doi:10.1016/j.rse.2013.08.028, 2014a.

Pope, A. and Rees, W. G.: Using in situ Spectra to Explore Landsat Classification of Glacier Surfaces, Int. J. Appl. Earth Obs., 27, 42-52, doi:10.1016/j.jag.2013.08.007, 2014b.

Pope, R. M. and Fry, E. S.: Absorption spectrum $~ 380-700 \mathrm{~nm}$ of pure water. II. Integrating cavity measurements, Appl. Optics, 36, 8710-8723, 1997.

Roy, D. P., Wulder, M. A., Loveland, T. R., C.E., W., Allen, R. G., Anderson, M. C., Helder, D., Irons, J. R., Johnson, D. M., Kennedy, R., Scambos, T. A., Schaaf, C. B., Schott, J. R., Sheng, Y., Vermote, E. F., Belward, A. S., Bindschadler, R., Cohen, W. B., Gao, F., Hipple, J. D., Hostert, P., Huntington, J., Justice, C. O., Kilic, A., Kovalskyy, V., Lee, Z. P., Lymburner, L., Masek, J. G., McCorkel, J., Shuai, Y., Trezza, R., Vogelmann, J., Wynne, R. H., and Zhu, Z.: Landsat-8: Science and product vision for terrestrial global change research, Remote Sens. Environ., 145, 154-172, doi:10.1016/j.rse.2014.02.001, 2014.
Selmes, N., Murray, T., and James, T. D.: Fast draining lakes on the Greenland Ice Sheet, Geophys. Res. Lett., 38, L15501, doi:10.1029/2011GL047872, 2011.

Shean, D. E., Alexandrov, O., Moratto, Z. M., Smith, B. E., Joughin, I. R., Porter, C. C., and Morin, P. J.: An automated, open-source pipeline for mass production of digital elevation models (DEMs) from very-high-resolution commercial stereo satellite imagery, ISPRS J. Photogramm. Remote Sens., in press, 2016.

Smith, L. C., Chu, V. W., Yang, K., Gleason, C. J., Pitcher, L. H., Rennermalm, A. K., Legleiter, C. J., Behar, A. E., Overstreet, B. T., Moustafa, S. E., Tedesco, M., Forster, R. R., LeWinter, A. L., Finnegan, D. C., Sheng, Y., and Balog, J.: Efficient meltwater drainage through supraglacial streams and rivers on the southwest Greenland ice sheet, P. Natl. Acad. Sci. USA, 112, 10011006, doi:10.1073/pnas.1413024112, 2015.

Smith, R. C. and Baker, K. S.: Optical properties of the clearest natural waters (200-800 nm), Appl. Optics, 20, 177-184, 1981.

Sneed, W. A. and Hamilton, G.: Evolution of melt pond volume on the surface of the Greenland Ice Sheet, Geophys. Res. Lett., 34, L03501, doi:10.1029/2006GL028697, 2007.

Sneed, W. A. and Hamilton, G. S.: Validation of a method for determining the depth of glacial melt ponds using satellite imagery, Ann. Glaciol., 52, 15-22, 2011.

Stevens, L. A., Behn, M. D., McGuire, J. J., Das, S. B., Joughin, I., Herring, T., Shean, D. E., and King, M. A.: Greenland supraglacial lake drainages triggered by hydrologically induced basal slip, Nature, 522, 73-76, doi:10.1038/nature14480, 2015.

Stumpf, R. P., Holderied, K., and Sinclair, M.: Determination of water depth with high-resolution satellite imagery over variable bottom types, Limnol. Oceanogr., 48, 547-556, doi:10.4319/lo.2003.48.1_part_2.0547, 2003.

Sundal, A. V., Shepherd, A., Nienow, P., Hanna, E., Palmer, S., and Huybrechts, P.: Melt-induced speed-up of Greenland ice sheet offset by efficient subglacial drainage, Nature, 469, 521-524, doi:10.1038/nature09740, 2011.

Tedesco, M. and Steiner, N.: In-situ multispectral and bathymetric measurements over a supraglacial lake in western Greenland using a remotely controlled watercraft, The Cryosphere, 5, 445452, doi:10.5194/tc-5-445-2011, 2011.

Tedesco, M., Lüthje, M., Steffen, K., Steiner, N., Fettweis, X., Willis, I., Bayou, N., and Banwell, A.: Measurement and modeling of ablation of the bottom of supraglacial lakes in western Greenland, Geophys. Res. Lett., 39, L02502, doi:201210.1029/2011GL049882, 2012.

Tedesco, M., Willis, I. C., Hoffman, M. J., Banwell, A. F., Alexander, P., and Arnold, N. S.: Ice dynamic response to two modes of surface lake drainage on the Greenland ice sheet, Environ. Res. Lett., 8, 034007, doi:10.1088/1748-9326/8/3/034007, 2013.

Tedesco, M., Steiner, N., and Pope, A.: In situ spectral reflectance and depth of a supraglacial lake in Greenland, UCAR-NCAR CISL ACADIS, doi:10.5065/D6FQ9TN2, 2015.

van den Broeke, M. R., Smeets, C. J. P. P., and van de Wal, R. S. W.: The seasonal cycle and interannual variability of surface energy balance and melt in the ablation zone of the west Greenland ice sheet, The Cryosphere, 5, 377-390, doi:10.5194/tc-5-377-2011, 2011.

USGS: Using the USGS Landsat 8 Product, available at: http: //landsat.usgs.gov/Landsat8_Using_Product.php (last acces: 4 April 2015), 2013. 
Willis, M. J., Herried, B. G., Bevis, M. G., and Bell, R. E.: Recharge of a subglacial lake by surface meltwater in northeast Greenland, Nature, 518, 223-227, doi:10.1038/nature14116, 2015.
Zwally, H. J., Abdalati, W., Herring, T., Larson, K. M., Saba, J. L., and Steffen, K.: Surface Melt-Induced Acceleration of Greenland Ice-Sheet Flow, Science, 297, 218-222, 2002. 